\title{
Analysis of the Benzodiazepine Prescribing Patterns in the Primary Healthcare of the Republic of Srpska
}

\author{
Žana Maksimović ${ }^{1,2}$, Mladen Stajić1,2, Dragana Lončar-Stojiljković3
}

\section{ABSTRACT}

Background: Benzodiazepines (BZDs) are very often inappropriately prescribed drugs. The aim of this study is to analyse physicians' prescribing patterns for BZD in Republic of Srpska, and to assess to what extent primary diagnosis determine the dose and the length of use of BZDs.

Methods: A retrospective analysis of the physicians' prescription habits based on the database of Family Medicine Information Systems of Republic of Srpska, as well as on data from patient's medical record were performed. Patients' socio-demographic and clinical characteristics, including the data on the type and dose of BZDs prescribed, were recorded and evaluated.

Results: BZDs were mostly prescribed for anxiety disorders (30.05\%), for depressive disorders (17.54\%), and for anxiety-depressive disorders (10.86\%). A significant amount of BZDs was prescribed for non-psychiatric diagnoses (23.81\%). Patients suffering from psychotic disorders were taking the highest dose of BZD and for the longest periods of time $(\mathrm{p}<0.001)$. Longer use of BZDs was in women $(\mathrm{r}=0.04, \mathrm{p}<0.001)$, elderly $(\mathrm{r}=0.178, \mathrm{p}<0.001)$, single people $(\mathrm{r}=0.12, \mathrm{p}<0.001)$, those who live in urban areas $(\mathrm{r}=0.45, \mathrm{p}<0.001)$ and those who were prescribed higher doses $(\mathrm{r}=0.213, \mathrm{p}<0.001)$.

Conclusion: A significant percentage of patients were using the BZDs for longer period of time than recommended. Strongest positive correlation was found between the dose and the length of use, which implies the addictive potential of BZDs. Since it has been noticed that prolonged use, or abuse is present regardless of the diagnosis, precaution is advised when prescribing BZDs even for acute diseases.

Key words: benzodiazepines, primary healthcare, analysis of medicine use, rational pharmacotherapy.
(1) Primary Healthcare Centre Modriča, the Republic of Srpska, Bosnia and Herzegovina.

(2) Centre for Biomedical Research, Faculty of Medicine, University of Banja Luka Banja Luka, the Republic of Srpska, Bosnia and Herzegovina.

(3) Institute for Cardiovascular Diseases "Dedinje", Belgrade, Serbia

\section{Correspondence:}

ŽANA MAKSIMOVIĆ

E: maksimoviczana85@gmail.com M: +38765970 593

\section{ARTICLE INFO}

Received: 8 June 2019

Revision received: 20 June 2019

Accepted: 24 June 2019

\section{INTRODUCTION}

Benzodiazepines (BZDs) are agonists of the BZD receptors at the $\gamma$-amino-butyric acid A (GABA-A) receptor complex. The effect of stimulation of GABA receptors provides its anxiolytic, sedative, hypnotic, anticonvulsant and myorelaxant effect. ${ }^{1}$ BZDs are used in treatment of insomnia, anxiety disorders and along with antidepressant. ${ }^{2}$ They are also used in the treatment of terminally ill cancer patients. ${ }^{3}$ According to current guidelines the use of BZD should be limited to shorter use (up to 4 weeks) to minimize the risk of adverse reactions (e.g. dependence or withdrawal symptoms). ${ }^{4,5}$ However, it is estimated that $3 \%$ of the general population use BZD for the period longer than 6 months in continuity. ${ }^{6}$ The long term use of these drugs is potentially inappropriate and can cause a range of adverse side effects including cognitive and psychomotor impairment, particularly in older patients. 
Most authors agree that use of BZDs for longer than 6 months suggests addiction. Abuse of opiates and BZDs is often coinciding. ${ }^{8}$ Longer use of BZDs, especially in the elderly, is correlated with frequent falls, moderate risk of all causes of death and dementia. ${ }^{8-12}$ Despite lack of recommendations, BZDs are often used for treatment of pain and somatic disorders. Furthermore, there are even relative contraindications for use of BZDs in patients suffering from schizophrenia, and in patients with psychotic disorders BZDs should only be used for very short sedation and calming down of acutely agitated patients. ${ }^{13,14}$

The aim of this study is to evaluate physicians' habits in prescribing of BZD in the primary health care settings of Republic of Srpska, and to assess to what extent the primary diagnosis determines the dose and the length of use of BZDs.

\section{METHODS}

Retrospective cross-sectional study was conducted. Doctors prescribing practice data in primary healthcare were collected from the Family Medicine Information Systems (WebMedic) of Republic of Srpska. Anonymity of patients was preserved. Personal medical record of each patient was coded, without data related to patients' name, initials or personal identification number. Only data of patients age and sex were available.

\section{Prescription analysis}

All patients that had been using BZDs from February 2011 to February 2018 were included in this study. Basic socio-demographic and clinical data such as: gender (male/female), age (years), smoking status (smoking/not smoking), place of residence (urban environment: municipality population $\geq 20$, 000 inhabitants / rural environment: municipality population $<20$,000 inhabitants), marital status (married/single), prescribing diagnosis for BZDs, existence and type of comorbidity were analysed.

For easier comparison, all diagnoses for which BZDs were prescribed are grouped as follows: (1) mixed anxiety-depressive disorder; (2) anxiety disorders; (3) depressive disorders; (4) psychotic disorders; (5) other psychiatric disorders (psychiatric diagnoses that do not fit into the first four groups); (6) non-psychiatric disorders. To compare different doses of BZDs, a table of equivalence was used. Equivalent dose (ED) matches the clinical equivalence when a patient is 'switched' from one BZD to another, and ED = 1 matches $10 \mathrm{mg}$ diazepam and equivalent doses of other BZDs. ${ }^{15,16}$ Furthermore, for easier comparison, based on their elimination half-lives, BZDs were grouped as: short-acting BZDs (halflife $<12 \mathrm{~h}$ ), intermediate-acting BZDs (half-life 12-24 h) and long-acting BZDs (half-life $>24$ h) (Table 1). For significant number of patients, the combination of two different BZDs, from the same or different BZD subgroups, had been prescribed and these patients were put in a separate, fourth category. ${ }^{15,17}$

Table 1: Duration of action and equivalent doses of BZD

\begin{tabular}{|c|c|c|}
\hline Duration of BZD action & INN & ED \\
\hline \multirow{4}{*}{$\begin{array}{l}\text { Short-acting } \\
(\mathrm{t} / 2<12 \mathrm{~h})\end{array}$} & alprazolam & $0.5 \mathrm{mg}$ \\
\hline & brotizolam & $0.25 \mathrm{mg}$ \\
\hline & midazolam & $5 \mathrm{mg}$ \\
\hline & oxazepam & $20 \mathrm{mg}$ \\
\hline \multirow{3}{*}{$\begin{array}{l}\text { Intermediate-acting } \\
(\mathrm{t} / 2=12-24 \mathrm{~h})\end{array}$} & bromazepam & $5 \mathrm{mg}$ \\
\hline & lorazepam & $1 \mathrm{mg}$ \\
\hline & nitrazepam & $10 \mathrm{mg}$ \\
\hline \multirow{7}{*}{$\begin{array}{l}\text { Long-acting } \\
(\mathrm{t} / 2>24 \mathrm{~h})\end{array}$} & diazepam & $10 \mathrm{mg}$ \\
\hline & clorazepate & $15 \mathrm{mg}$ \\
\hline & flurazepam & $20 \mathrm{mg}$ \\
\hline & clobazam & $20 \mathrm{mg}$ \\
\hline & clonazepam & $0.5 \mathrm{mg}$ \\
\hline & medazepam & $10 \mathrm{mg}$ \\
\hline & prazepam & $10 \mathrm{mg}$ \\
\hline
\end{tabular}

BZD-benzodiazepine; t/2-half-life; INN-international nonproprietary name; ED-equivalent dose

\section{RESULTS}

Total number of prescriptions of all drugs for all years amounted $37,741,591$. Number of patients in the database was $1,422,931$. Number of prescriptions of BZDs for all years amounted $1,125,632$ (2.98\% of all prescriptions). That number of prescriptions was prescribed to 151,204 different patients $(10.63 \%$ of all patients). Socio-demographical differences are shown in Table 2. Two thirds of the patients to whom BZDs had been prescribed were women. Average age of patients was 60 , with only $1 / 10$ of patients being younger than 40, and half of the patients aging 41-65. Two thirds of patients were single. Again, two thirds of patients lived in urban areas. Of the sample of 515 patients, 
3/4 were non-smokers, while 139 were smokers (26.99\%). (Table 2).

Table 2: Socio-demographic characteristics of benzodiazepine users

\begin{tabular}{|c|c|c|}
\hline Variable & $\mathbf{N}$ & $\%$ \\
\hline \multicolumn{3}{|l|}{ Sex } \\
\hline Male & 52254 & 52254 \\
\hline Female & 98950 & 98950 \\
\hline \multicolumn{3}{|c|}{ Age (Mean (SD): 60.46 (15.00) } \\
\hline$\leq 40$ years & 16782 & 11.10 \\
\hline 41- 65 years & 74731 & 49.42 \\
\hline$\geq 66$ years & 59691 & 39.48 \\
\hline \multicolumn{3}{|l|}{ Marital status } \\
\hline Married & 59781 & 39.54 \\
\hline Single & 91423 & 60.46 \\
\hline \multicolumn{3}{|l|}{ Place of residence } \\
\hline Urban areas & 105365 & 69.68 \\
\hline Rural areas & 45839 & 30.32 \\
\hline TOTAL & 151204 & 100.00 \\
\hline \multicolumn{3}{|l|}{ Smoking status } \\
\hline Smokers & 376 & 73.01 \\
\hline Non-smokers & 139 & 26.99 \\
\hline TOTAL & 515 & 100.00 \\
\hline
\end{tabular}

$\mathrm{N}=$ number of patients; $\mathrm{SD}=$ standard deviation

Half of the patients used BZDs for the recommended 3 months. The other half used them longer; 30\% even longer than 10 months, averaging in total 5.5 months. Spearman's correlation showed that longer use of BZDs occurred in women $(\mathrm{r}=0.04, \mathrm{p}<0.001)$, elderly $(\mathrm{r}=0.178, \mathrm{p}<0.001)$, single patients $(\mathrm{r}=0.12$, $\mathrm{p}<0.001)$, those who live in urban areas $(\mathrm{r}=0.45$, $\mathrm{p}<0.001)$ and those who use higher doses of BZDs ( $\mathrm{r}=0.213, \mathrm{p}<0.001)$. There was no significance in the smoking status of patients $(r=0.60$, $\mathrm{p}=0.171)$.

Average dose per patient amounted o.88 ED. Two thirds used less than $1 \mathrm{ED}$, but $5.39 \%$ used 2-3 EDs, and $3.37 \%$ used a dose higher than 4 EDs. Spearman's correlation showed that higher dose was associated with men $(\mathrm{r}=0.81$, $\mathrm{p}<0.001)$, married patients $(\mathrm{r}=0.20, \mathrm{p}<0.001)$, younger patients $(\mathrm{r}=0.55, \mathrm{p}<0.001)$, smokers $(\mathrm{r}=0.16, \mathrm{p}<0.001)$ and those who live in rural areas $(\mathrm{r}=0.22, \mathrm{p}<0.001)$.

BZDs were mostly prescribed for anxiety disorders. A significant amount of BZDs was pre- scribed for non-psychiatric diagnoses. Data related to the diagnosis, dosage and length of use of BZDs are shown in Table 3. Patients suffering from psychotic disorders received highest doses (Kruskal-Wallis test: $\chi 2=7504.63, \mathrm{p}<0.001$ ), followed by patients suffering from depressive disorders. Lowest doses were used by patients suffering from non-psychiatric disorders. Patients suffering from psychotic disorders have been taking BZDs for longest periods of time (Kruskal-Wallis test $\chi^{2}=755.02, p<0.001$ ), followed by patients suffering from depressive disorders. Patients suffering from anxiety disorders have been taking BZD for the shortest periods of time, followed by patients with nonpsychiatric disorders. (Table 3).

Table 3: Average dose and lenght of use of benzodiazepines depending on diagnosis

\begin{tabular}{|c|c|c|c|c|}
\hline Diagnosis (group) & $\mathbf{N}$ & $\%$ & ED & $\begin{array}{l}\text { Length } \\
\text { of use } \\
\text { (in months)* }\end{array}$ \\
\hline 1. Anxiety-depressive disorder & 16422 & 10.86 & $1.25(1.21)$ & $5.38(4.32)$ \\
\hline 2. Anxiety disorders & 45432 & 30.05 & $0.97(0.96)$ & $5.09(4.33)$ \\
\hline 3. Depressive disorders & 26516 & 17.54 & $1.48(1.43)$ & $5.93(4.46)$ \\
\hline 4. Psychotic disorders & 7925 & 5.24 & $1.87(1.56)$ & $6.86(4.56)$ \\
\hline 5. Other psychiatric disorders & 18904 & 12.50 & $1.21(1.21)$ & $5.50(4.42)$ \\
\hline 6. Non-psychiatric disorders & 36005 & 23.81 & $0.77(0.73)$ & $5.27(4.36)$ \\
\hline TOTAL: & 151204 & 100.00 & $1.13(1.15)$ & $5.46(4.40)$ \\
\hline
\end{tabular}

*Mean (SD); N: number of patients; ${ }^{\star \star} E D$ : approximately equvalent dosage between benzodiazepines, which 1 correspond with $10 \mathrm{mg}$ of diazepam.

Diagnosis had statistical impact on choice of BZDs $\quad(\chi 2=13747.23, \quad \mathrm{p}<0.001)$. Short-acting BZDs were most commonly prescribed for depressive and mixed anxio-depressive disorders, and least for psychotic and non-psychiatric disorders (Figure 1). Intermediate-acting BZDs were most commonly prescribed for non-psychiatric and anxiety disorders, and least for psychotic disorders. Patients suffering from psychotic disorders, used long-acting BZDs (even more than intermediate-acting), and this was the only group in any category, that did not prefer intermediate-acting BZD. Patients that suffer from depressive and mixed anxiety-depressive disorders more often than other patients used different BZDs. (Figure 1 near here).

Since it was noticed that BZD had been prescribed to a significant percentage of patients based on non-psychiatric diagnosis, further analysis was conducted. Within the non-psychi- 


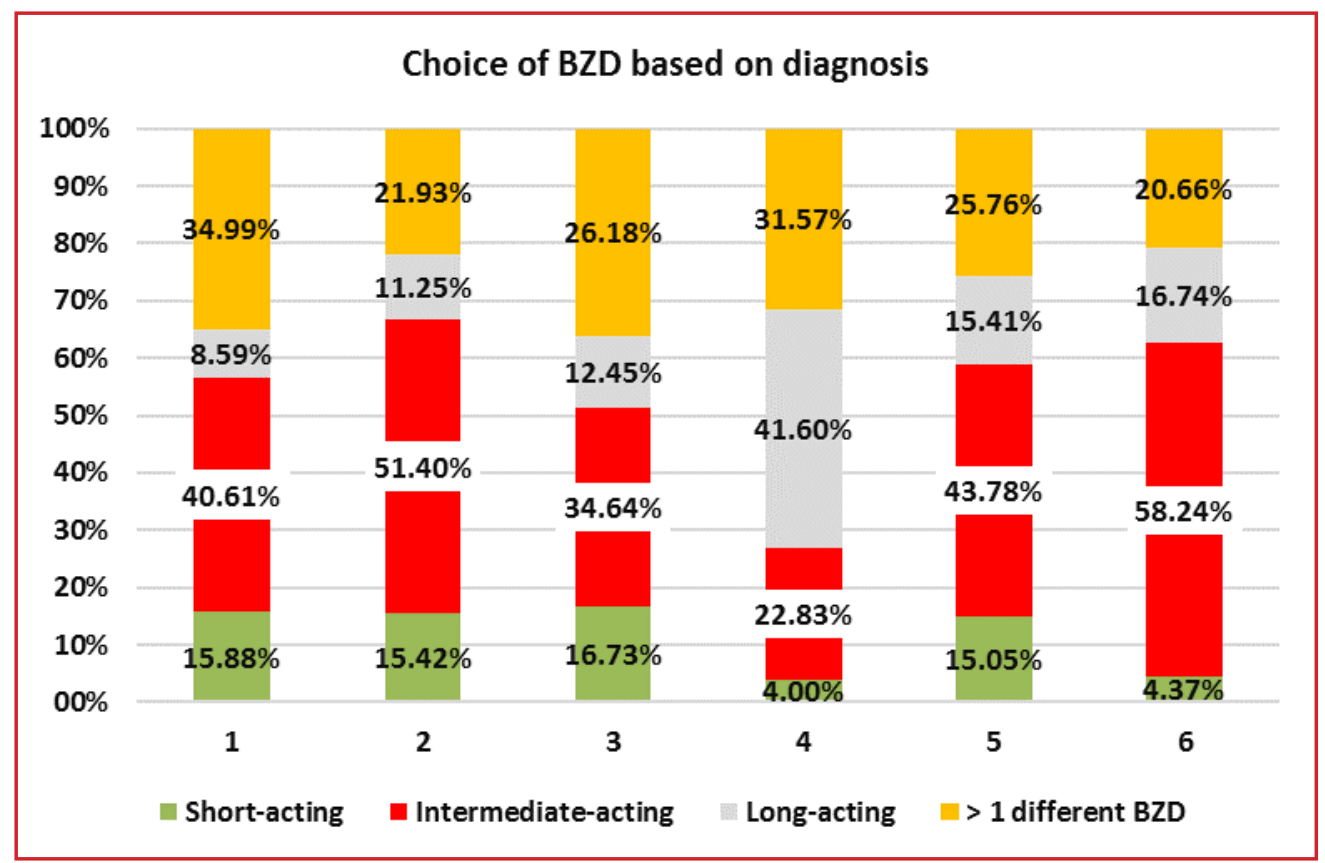

Figure 1. Choice of benzodiazepines based on diagnosis:

Diagnosis: 1 - Mixed anxiety-depressive disorder; 2 - Anxiety disorders; 3 - Depressive disorders; 4 - Psychotic disorders; 5 - 0ther psychiatric disorders; 6 - Non-psychiatric disorders.

atric group of disorders musculoskeletal diseases were the most common reason for prescribing BZD (29.16\%), followed by epilepsy (22.92\%), hypertension (13.54\%), arrhythmias (9.38\%) and chest pain (6.25\%). Other diseases, such as headache, vertigo, etc. were presented less often. More than 4/5 patients to whom BZDs were prescribed had one or more comorbidities. Most common comorbidity was hypertension. Patients who had more than three chronical diseases and used more than five different drugs every day were set aside to a separate category. Existence and type of comorbidity, as well as their average dose and lenght of their use is shown in Table 4.

Table 4: Type of comorbidity, average dose and lenght of use of benzodiazepines

\begin{tabular}{|c|c|c|c|}
\hline Diagnosis (group) & N (\%) & $\begin{array}{l}\text { Length } \\
\text { of use } \\
\text { (in months) }^{\star}\end{array}$ & Dosage (ED)* \\
\hline No comorbidity & $84(16.31)$ & $7.17(4.89)$ & $1.18(1.06)^{\star \star}$ \\
\hline Hypertension & $215(41.7)$ & $8.30(3.93)$ & $0.84(0.73)^{\star \star}$ \\
\hline Other cardiovascular diseases & $25(4.85)$ & $8.08(4.30)$ & $0.76(0.40)$ \\
\hline Diabetes mellitus & $15(2.91)$ & $8.67(3.80)$ & $1.19(1.85)$ \\
\hline Musculosceletar diseases & $25(4.85)$ & $7.92(4.26)$ & $1.16(0.91)$ \\
\hline Other diseases & $40(7.77)$ & $7.58(4.84)$ & $1.33(1.36)$ \\
\hline Multiple comorbidities & $111(21.55)$ & $8.20(3.99)$ & $1.01(1.35)$ \\
\hline TOTAL & $515(100)$ & $8.02(4.21)$ & $0.99(1.05)$ \\
\hline
\end{tabular}

There was no statistical significance in length of use between patients who do or do not have comorbidities (Man-Whitney $\mathrm{U}$ test: $\mathrm{U}=1623.00$, $\mathrm{p}=0.12$ ), as well as among the particular types of comorbidity (Kruskal-Wallis test: $\chi^{2}=0.48$, $\mathrm{p}=0.99$ ). Patients who did not have any comorbidity used higher dosage in comparison with those who did ( $U=14532.00, p=0.04)$. Based on type of comorbidity, patients who only had hypertension as comorbidity used lower dose than the others, except for patients suffering from other cardiovascular diseases (Kruskal-Wallis test showed general statistical significance $\chi 2=12.40, p=0.03$; further post-hoc analysis showed statistical significance only for hypertension).

\section{DISCUSSION}

The results of this study showed that BZDs were mainly prescribed to women as well as to older patients. Women have been taking BZDs almost twice as often as men, and studies from other countries showed similar results. ${ }^{18-26}$ BZDs were used mainly by older patients and also for longer time compared to younger patients, which corresponds to studies from abroad that classified BZDs, specifically long-acting BZDs, as top 5 most inappropriately prescribed drugs in the 
elderly. ${ }^{18,20,21,25-30}$ In terms of correlations, there was a statistically significant negative correlation between the dose of BZD and the age patients - the older the age, the smaller the daily dose. This finding is in accordance with global findings, which also state that older patients use smaller doses of BZDs, which is logical, based on the narrow therapeutic width of BZDs in the elderly population, due to lower creatinine clearance values, reduced liver functionality, polypharmacy and interaction with other drugs and reduced body weight. ${ }^{21,25,29,30}$ When it comes to marital status, nearly $60 \%$ of patients were single. That coincides with results of published studies. ${ }^{29,31}$ Our results show that patients from urban areas tend to use BZDs more often than those living in rural areas (70\%:30\%). Other studies comparing incidence of depressive and anxiety disorders showed that mood disorders occur more often in patients from urban areas compared to the rural ones. ${ }^{32}$ Also, citizens of urban areas take BZDs for longer periods of time. ${ }^{33-35}$ This is somewhat logical taking in consideration faster life style, noise, traffic, air pollution and other factors that citizens of urban areas are more exposed to.

The percentage of smokers in the examined sample matched the estimated percentage of smokers in Republic of Srpska. Data show that smokers use significantly larger doses of BZDs, which corresponds the data from the literature. ${ }^{25}$ Furthermore, this study showed that there were more smokers among the users of long-acting BZDs. This is probably due to the fact that smokers are being generally more anxious, with weaker impulse control, so they need a stronger and longer-lasting anxiolytic effect. ${ }^{36,37}$

Based on the diagnosis, use of BZDs is expectedly high in patients with anxiety and depressive disorders, but unusually high (23.8\%) in patients with non-psychiatric disorders. Some regional studies show a high trend of prescribing BZDs to hypertensive patients, but it is known from primary care practice that the trend exists in other non-psychiatric disorders (low back pain, diabetes, myalgia, headache), as was confirmed by our findings. ${ }^{38,39}$ One of the reasons for such a high percentage of prescribed BZDs for non-psychiatric disorders could also be the lack of care by family medicine physicians when it comes to making a diagnosis. Doctors may have thought that anxiety of the patient makes the primary disease worse, but they did not find it necessary to introduce officially into patient's record the diagnosis of anxiety or mixed mood disorder. Prescription of BZDs in mentioned indications is justified, but lenght of their use in these indications is troubling. For example, BZDs have been used for such a long time for low back pain and for anxiety-depressive disorders. Evidently, prolonged usage, or abuse, of BZDs is equally present regardless of the diagnosis.

Short-acting BZDs were most often prescribed to patients suffering from depressive and mixed anxio-depressive disorders, which is logical when taking in consideration that they have the fastest onset of therapeutic effect, and patients take them to control acute anxiety attacks. It would be logical that they are prescribed most frequently in patients with anxiety disorders as well, however intermediate-acting BZDs are most frequently prescribed in these disorders. Long-acting BZDs are most often prescribed in patients with psychotic disorders. Reason for this is probably that the agitated psychotic patient needs to be sedated for the longest period possible.

When comparing the dose and the length of use with diagnosis, it was apparent that patients with anxiety and psychotic disorders are prescribed with both highest doses and for the longest period of time, whereas patients with non-psychiatric disorders receive the smallest doses. Prescription of BZDs to patients with psychotic disorders is not in accordance with guidelines, especially during longer period of time. However, prescription of BZDs to patients suffering from schizophrenia is only justified for acute treatment of agitated patients. Same patients use BZDs for the longest periods of time, and use long-acting BZDs the most often. Patients suffering from psychotic disorders fit the only group that takes long-acting BZD more often compared to intermediate-acting ones. Length of use of BZDs in patients with psychotic disorders is totally opposite from the guidelines. Possible reasons are fear and prejudice of doctors towards these patients, and the need to calm these patients down, even though the stabilisation of mood in these patients is not achieved with use of BZDs. Larger doses in patients with depressive disorders would be justified if the length of use was shorter. In all new depressive episodes, along with an antidepressant an anxiolytic is also introduced, 
but it is recommended that the dose should start to decrease after three weeks until complete discontinuation of its use. Taken in consideration that this was not the case in these results, this is an example of poor prescribing practice. Both shortest length of use and smallest dose of BZDs were prescribed to patients with non-psychiatric disorders, which is logical given that these are usually temporary conditions. High blood pressure episode in acute stress reaction (which should be treated with anxiolytics) is often miscategorised as hypertension, rather than a psychiatric disorder. Worldwide studies showed that patients with sleeping disorders, dementia and depression use BZDs for longest time periods. ${ }^{39,40}$

Existence and type of comorbidity had no effect on lenght of use of BZDs, which is somewhat logical, considering that primary diagnosis should be a reason for shorter or longer lenght of use, not a comorbidity. Patients without comorbidities compared to those with comorbidities used higher doses, which is justified. ${ }^{39}$ However, further analysis showed that lower dose was prescribed only to patients that suffer from cardiovascular diseases, including hypertension, and other diseases were not taken into consideration. Lack of reduction of the BZD dose, especially in patients who had more than three chronic diseases and used more than five different drugs every day is highly alarming. Unfortunately, this is also an example of poor prescribing practice, considering that interactions among drugs in polypharmacy is very often. Family doctor, as a psysician able to see the entire medical history of a patient, must take a responsibility, if necessary, for reduction of dose if psychiatrist, or other specialist, overlooked polypharmacy..$^{41,42}$

In conclusion, a significant percentage of patients were using the BZDs for a longer time period than recommended. Strongest positive correlation was found between dose and longer use, which implies addictive potential of BZDs. Since it has been noticed that prolonged use, or abuse is present regarding the diagnosis, precaution is advised when prescribing BZDs even for acute diseases.

\section{ACKNOWLEDGEMENTS}

None.

\section{CONFLICT OF INTEREST}

None.

\section{REFERENCES}

1. Roy-Byrne PP. The GABA-benzodiazepine receptor complex: structure, function, and role in anxiety. $\mathrm{J}$ Clin Psychiatry 2005;66 Suppl 2:14-20.

2. Winkler A, Auer C, Doering BK, Rief W. Drug treatment of primary insomnia: a meta-analysis of polysomographic randomized controled trials. CNS Drugs 2014 Sep;28(9):799-816.

3. Lindqvist O, Lundquist G, Dickman A, Bükki J, Lunder U, Hagelin CL, et al. Four essential drugs needed for quality care of the dying: a Delphi-study based international expert consensus opinion. J Palliat Med 2013;16(1):38-43.

4. Benzodiazepine Committee. Benzodiazepines: good practice guidelines for clinicians [Internet]. Dublin: Department of Health and Children; 2002 [cited 2015 Jul 20]. Available from: http://www.drugsandalcohol. ie/5349/

5. The Royal Australian College of General Practitioners. Prescribing drugs of dependence in general practice, Part B - benzodiazepines [Internet]. Victoria (AU): The Royal Australian College of General Practitioners; 2015 [cited 2017 Aug 8]. Available from: http://www. drugsandalcohol.ie/24380/

6. Kurko TA, Saastamoinen LK, Tahkapaa S, Tuulio-Henriksson A, Taiminen $\mathrm{T}$, Tiihonen $\mathrm{J}$, et al. Long-term use of benzodiazepines: definitions, prevalence and usage patterns - a systematic review of register-based studies. Eur Psychiatry 2015;30:1037-47.

7. Lader M. Benzodiazepine harm: how can it be reduced? Br J Clin Pharmacol 2014;77:295-301.

8. Jones JD, Mogali S, Comer SD. Polydrug abuse: a review of opioid and benzodiazepine combination use. Drug Alcohol Depend 2012;125(1-2):8-18.

9. Hooft CS, Schoofs MW, Ziere G, Hofman A, Pols HA, Sturkenboom MC, et al. Inappropriate benzodiazepine use in older adults and the risk of fracture. $\mathrm{Br} \mathrm{J}$ Clin Pharmacol 2008;66:276-82.

10. Park H, Satoh H, Miki A, Urushihara H, Sawada Y. Medications associated with falls in older people: systematic review of publications from a recent 5-year period. Eur J Clin Pharmacol 2015;71(12):1429-40.

11. Palmaro A, Dupouy J, Lapeyre-Mestre M. Benzodiazepines and risk of death: Results from two large cohort studies in France and UK. Eur Neuropsychopharmacol 2015;25(10):1566-77.

12. Zhong G, Wang Y, Zhang Y, Zhao Y. Association between benzodiazepine use and dementia: a meta-analysis. PLoS One 2015 May 27;10(5):e0127836.

13. Dold M, Li C, Tardy M, Khorsand V, Gillies D, Leucht S. Benzodiazepines for schizophrenia. Cochrane Database Syst Rev 2012 Nov 14;11:CDoo6391.

14. Sim F, Sweetman I, Kapur S, Patel MX. Re-examining 
the role of benzodiazepines in the treatment of schizophrenia: a systematic review. J Psychopharmacol 2015;29(2):212-23.

15. Benzo.org.uk. The resource site for involuntary benzodiazepine tranquiliser addiction, withdrawal \& recovery. Benzodiazepine equivalence table [Internet]. Newcastle upon Type: Benzo.org.uk; 2016 [cited 2019Apr-10]. Available from: http://www.benzo.org.uk/ bzequiv.htm.

16. WHO Collaborating Centre for Drug Statistics Methodology. ATC/DDD System [Internet]. Oslo (NO): WHO Collaborating Centre for Drug Statistics Methodology; 2009 [cited 2019-Apr-10]. Available from: https://www.whocc.no/atc_ddd_index/

17. Medscape. Benzodiazepine equivalency table [Internet]. New York, NY (USA): Medscape; 2018 Jul 31 [cited 2019-Apr-10]. Available from: http://emedicine. medscape.com/article/2172250-overview

18. Sonnenberg CM, Bierman E, Deeg D, Comijs H, Tilburg W, Beekman A. Ten-year trends in benzodiazepine use in the Dutch population. Soc Psychiatry Psychiatr Epidemiol 2012;47(2):293-301.

19. Manthey L, van Veen T, Giltay E, Stoop J, Neven AK, Penninx B, et al. Correlates of inappropriate benzodiazepine use: the Netherlands Study of Depression and Anxiety (NESDA). Br J Clin Pharmacol 2011;71(2):263-72.

20. Cahir C, Fahey T, Telling M, Teljeur C, Feely J, Bennett K. Potentialy inappropriate prescribing and cost outcomes for older people: a national population study. $\mathrm{Br}$ J Clin Pharmacol 2010;69(5):543-52.

21. Alvarenga JM, Loyola Filho AI, Firmo JOA, Lima-Costa MF, Uchoa E. Prevalence and sociodemographic characteristics associated with benzodiazepines use among community dwelling older adults: the Bambuí Health and Aging Study (BHAS). Rev Bras Psiquiatr 2008;30(1):7-11.

22. Ramadan W, Khoury G, Deeb M, Sheikh-Taka M. Prescription patterns of benzodiazepines in the Lebanese adult population: a cross-sectional study. Neuropsychiatr Dis Treat 2016;12:2299-305.

23. Olfson M, King M, Schoenbaum M. Benzodiazepine use in the United States. JAMA Psychiatry 2015;72(2):136-42.

24. Boyd A, Van de Velde S, Pivette M, Ten Have M, Florescu S, O'Neill S, et al; EU-WMH investigators. Gender differences in psychotropic use across Europe: results from a large cross-sectional, population-based study. Eur Psychiatry 2015;30(6):778-88.

25. Nordfjærn T, Bjerkeset O, Bratberg G, Moylan S, Berk M, Gråwe R. Socio-demographic, lifestyle and psychological predictors of benzodiazepine and z-hypnotic use patterns. Nord J Psychiatry 2014;68(2):107-16.

26. Cadogan CA, Ryan C, Cahir C, Bradley CP, Bennett $\mathrm{K}$. Benzodiazepine and Z-drug prescribing in Ireland: analysis of national prescribing trends from 2005 to 2015. Br J Clin Pharmacol 2018;84(6):1354-63.

27. Maust DT, Lin LA, Blow FC. Benzodiazepine use and misuse among adults in the United States. Psychiatr Serv 2019;70(2):97-106.
28. Panes A, Pariente A, Bénard-Laribière A, Lassalle R, Dureau-Pournin C, Lorrain S, et al. Use of benzodiazepines and z-drugs not compliant with guidelines and associated factors: a population-based study. Eur Arch Psychiatry Clin Neurosci 2018 Dec 11. doi: 10.1007/ so0406-018-0966-3. [Epub ahead of print]

29. Sundseth AC, Gjelstad S, Straand J, Rosvold EO. General practitioners' prescriptions of benzodiazepines, Z-hypnotics and opioid analgesics for elderly patients during direct and indirect contacts. A cross-sectional, observational study. Scand J Prim Health Care 2018;36(2):115-22.

30. Johnson CF, Frei C, Downes N, McTaggart SA, Akram G. Benzodiazepine and z-hypnotic prescribing for older people in primary care: a cross-sectional population-based study. Br J Gen Pract 2016;66(647):e410-5.

31. Tvete IF, Bjorner T, Skomedal T. Risk factors for excessive benzodiazepine use in a working age population: a nationwide 5-year survey in Norway. Scand J Prim Helath Care 2015;33(4):252-59.

32. Canham SL.What's loneliness got to do with it? Older women who use benzodiazepines. Australas J Ageing 2015;34(1):E7-E12.

33. Romans S, Cohen M, Forte T. Rates of depression and anxiety in urban and rural Canada. Soc Psychiatry Psychiatr Epidemiol 2011;46(7):567-75.

34. Subramaniam M, He VY, Vaingankar JA, Abdin E, Chong SA. Prevalence of and factors related to the use of antidepressants and benzodiazepines: results from the Singapore Mental Health Study. BMC Psychiatry 2013;13:231. doi: 10.1186/1471-244X-13-231.

35. Tahiri Z, Kellici S, Mone I, Shabani D, Qazimi M, Burazeri G. Prevalence and correlates of inappropriate use of benzodiazepines in Kosovo. Int $\mathrm{J}$ Clin Pharm 2017;39(4):669-73.

36. Liu SJ, Lan Y, Wu L, Yan WS. Profiles of impulsivity in problematic Internet users and cigarette smokers. Front Psychol 2019 Apr 4;10:772. doi: 10.3389/ fpsyg.2019.00772.

37. Choi J-S, Payne TJ, Ma JZ, Li MD. Relationship between personality traits and nicotine dependence in male and female smokers of African-American and European-American samples. Front Psychiatry 2017;8:122. doi: 10.3389/fpsyt.2017.00122.

38. Sirdifield C, Anthierens S, Creupelandt H, Chipchase SY, Christiaens T, Siriwardena AN. General practitioners' experiences and perceptions of benzodiazepine prescribing: systematic review and meta-synthesis. BMC Fam Pract 2013 Dec 13;14:191. doi: 10.1186/1471-2296-14-191.

39. Linnet K, Gudmundsson LS, Birgisdottir FG, Sigurdsson EL, Johannsson M, Tomasdottir MO, et al. Multimorbidity and use of hypnotic and anxiolytic drugs: cross-sectional and follow-up study in primary healthcare in Iceland. BMC Fam Pract. 2016 Jun 6;17:69. doi: 10.1186/s12875-016-0469-0.

40. Jacob L, Rapp MA, Kostev K. Long-term use of benzodiazepines in older patients in Germany: a retrospective analysis. Ther Adv Psychopharmacol 2017;7(67):191-200. 
41. Weiß V, Nau R, Glaeske G, Hummers E, Himmel W. The interplay of context factors in hypnotic and sedative prescription in primary and secondary care-a qualitative study. Eur J Clin Pharmacol 2019;75(1):8797.
42. Vicens C, Leiva A, Bejarano F, Sempere E, Rodríguez-Rincón RM, Fiol F, et al. Intervention to reduce benzodiazepine prescriptions in primary care, study protocol of a hybrid type 1 cluster randomised controlled trial: the BENZORED study. BMJ Open 2019 Jan 30;9(1):e022046. doi: 10.1136/bmjopen-2018-022046. 